\title{
Pojok Baca Digital: Media Penunjang Aktivitas Belajar Masa Pandemi Covid-19
}

Ika Zutiasari ${ }^{1}$, Universitas Negeri Malang, ika.zutiasari.fe@um.ac.id

Ika Putri Kurniasari², Universitas Negeri Malang, ika.putri.1703126@students.um.ac.id

Amirul Fikri³, Universitas Negeri Malang, amirul.fikri.1707316@students.um.ac.id

Kholilatul Umiyah ${ }^{4}$, Universitas Negeri Malang, kholilatul.umiyah.1701536@students.um.ac.id

Salsabilla Nur Rahmawati ${ }^{5}$, Universitas Negeri Malang, salsabilla.nur.1702216@ students.um.ac.id

\begin{abstract}
:
The Covid-19 Pandemic period has changed many settings in various fields of life. One area of life that is affected in this case is the field of education. The pandemic changed the rules in learning, which was originally free learning, which was conducted face-to-face between the teaching staff and students, and then changed to free online learning. Therefore, digital reading corner in this case is needed as a companion reference. Digital reading corner with inside there are various collections of learning material about mathematics, social science, English, short stories and some other general knowledge. Making this digital reading corner by using the method of preparation of community service activities, preparation of learning modules, and digital reading corner counseling. Preparation of activities here such as discussing the work program to be carried out by our group and contacting the village to confirm that the work program that we have chosen is our group's offering for the villagers. After everything has been determined what work program will be run, then the next step is to arrange modules in stages within three weeks, compile this module for disciplines from kindergarten to high school level and finally conduct counseling to Gading Kembar village. The results of this activity are in accordance with what is expected where all the relevant elements have responded well during our group's work program.
\end{abstract}

\section{Keywords: Covid-19 Pandemic, Digital Reading Corner, Learning Media}

\begin{abstract}
Abstrak:
Masa Pandemi Covid-19 ini telah mengubah banyak tatanan aturan dalam berbagai bidang kehidupan. Salah satu bidang yang terdampak dalam hal ini yakni bidang pendidikan. Pandemi mengubah aturan dalam pembelajaran yang awalnya merdeka belajar dilakukan secara tatap muka antara tenaga pendidik dengan peserta didik, diubah menjadi merdeka belajar secara online. Oleh karena itu, pojok baca digital dalam hal ini sangat dibutuhkan sebagai rujukan pendamping. Pojok baca digital dengan didalamnya terdapat berbagai materi pembelajaran mengenai matematika, ilmu pengetahuan sosial, Bahasa Inggris, Cerpen dan pengetahuan umum lainnya. Pembuatan pojok baca digital ini dengan menggunakan metode persiapan kegiatan pengabdian, penyusunan modul pembelajaran, dan penyuluhan. Persiapan kegiatan disini seperti berdiskusi mengenai program kerja yang akan dijalankan oleh kelompok kami dan menghubungi pihak desa untuk mengkonfirmasi bahwa program kerja yang kita pilih merupakan persembahan kami untuk warga desa. Setelah semuanya telah ditetapkan program kerja apa yang akan dijalankan, maka selanjutnya yaitu penyusunan modul secara bertahap dalam waktu tiga minggu, penyusunan modul ini untuk disiplin ilmu dari tingkat TK sampai SMA dan terakhir melakukan penyuluhan ke desa Gading Kembar. Hasil kegiatan ini sangat sesuai dengan yang diharapkan dimana semua elemen yang bersangkutan telah memberikan respon baik selama kelompok kami menjalankan program kerja ini.
\end{abstract}

Keywords: Pandemi Covid-19, Pojok Baca Digital, Media Pembelajaran

Copyright (C) 2021, Dinamis: Jurnal Pengabdian Kepada Masyarakat

https://ejournal.feunhasy.ac.id/dinamis 


\section{PENDAHULUAN}

Masa pandemi covid-19 ini telah mengubah kebiasaan hidup seseorang dalam seharisehari. Terutama pada bidang pendidikan, peserta didik banyak merasakan perubahan pola penyampaian materi yang terbiasa dengan bertatap muka secara langsung telah berganti menjadi penyampaian materi secara online. Penyampaian materi ini sangat beragam bentuknya, semua bergantung dan sesuai dengan tingkat disiplin ilmu. Penyampaian yang dimulai dari menggunakan media televisi TVRI, ini diperuntukkan bagi pelajar dari tingkat PAUD hingga SMA. Presentasi dan penyampaian materi bagi para mahasiswa dapat dilakukan secara online melalui beberapa aplikasi. Hal ini tentu telah mengubah kebiasaan merdeka belajar dari kalangan PAUD hingga Mahasiswa.

Salah satu contoh yang merasakan dampak ini yaitu para pelajar dari desa Gading Kembar. Desa Gading Kembar merupakan desa yang terletak di kecamatan Jabung, Kabupaten Malang. Desa yang terdiri dari empat dusun yakni dusun Gasek Kulon, dusun Gasek Wetan, dusun Gading, dan dusun Dempok. Jarak antar dusun kurang lebih 20 meter. Memiliki penduduk dengan jenjang pendidikan yang bervariatif, membuat desa ini sangat membutuhkan rujukan pendamping buku-buku yang ada disekolah.

Era digital seperti saat ini yang telah berkembang pesat selalu menuntut seseorang untuk dapat menggunakan teknologi secara baik dan efisien dalam menunjang segala aspek kehidupan. Pola pengajaran pun dituntut harus memiliki berbagai model yang inovatif dengan menggunakan teknologi digital. Salah satu contoh penggunaan teknologi digital dalam kategori pendidikan ini seperti membuat pojok baca digital yang didalamnya terdapat beberapa modu. Materi modul ini pun sangat beragam dari mulai Matematika, Ilmu Pengetahuan Sosial, Pendidikan Bahasa Inggris, cerpen dan beberapa modul pengetahuan umum lainnya.

Guru sebagai pendamping peserta didik perlu dibekali dengan pembelajaran inovatif menggunakan strategi literasi. Disini guru perlu menggalakkan betapa pentingnya literasi bagi para peserta didik dalam belajar. Konsep literasi ini dibagi menjadi enam kategori, yaitu literasi dini, literasi dasar, literasi perpustakaan, literasi media, literasi teknologi, dan literasi visual (Fadli et al., 2020). Para pemateri mengharapkan agar dengan adanya literasi pada sekolah ini dapat meningkatkan kualitas pendidikan di Indonesia. Disamping itu kurangnya minat baca anak-anak dan remaja disebabkan oleh beberapa faktor, seperti kurangnya daya beli dan kurangnya ketersediaan buku-buku bacaan umum dan pelajaran yang menarik untuk dibaca. Program pengabdian ini bertujuan membangun pojok baca dengan memperhatikan unsur ramah anak, yang tujuannya agar anak senang berkunjung dan minat baca anak semakin bertambah. (Habiburrahman \& Fatmawati, 2020). Literasi digital merupakan era perkembangan baru dunia baca tulis. Seluruh informasi dengan mudah diperoleh melalui media sosial. Semua berita disajikan dengan cepat, namun terkadang tidak akurat, karena kecepatan pemberitaan yang terpenting. Berbagai situs berita bermunculan, akun-akun komunitas bermunculan, dan sebagainya. Seperti dua sisi mata uang, era literasi digital dapat memperbaiki keadaan, dapat juga memperburuk keadaan. Peran orang tua sangat penting dalam hal ini untuk mengawasi tingkah laku anak dan remaja. Pemahaman literasi digital yang buruk akan berpengaruh pada psikologis anak dan remaja yang cenderung menghina orang lain, menimbulkan sikap iri 
Ika Zutiasari, Ika Putri Kurniasari, Amirul Fikri, Kholilatul Umiyah, Salsabilla 3 Nur Rahmawati: Pojok Baca Digital: Media Penunjang Aktivitas Belajar Masa Pandemi Covid-19

terhadap orang lain, mengakibatkan depresi, terbawa arus suasana hati terhadap komentar negatif, serta terbiasa berbicara dengan bahasa kurang sopan (Sutrisna, 2020). Gerakan literasi digital yang dapat dilakukan dalam masa pandemi covid-19 adalah gerakan literasi keluarga dan gerakan literasi masyarakat. Untuk mengantisipasi penyebaran berita hoaks pada masa pandemi covid-19, masyarakat perlu cermat dalam mencermati berita di media sosial. Di samping itu, masyarakat harus bijaksana dalam menggunakan media sosial dan saring sebelum sharing. Tulisan ini hanya menawarkan konsep pemikiran literasi digital, perlu diadakan penelitian lanjutan terkait literasi digital dalam kehidupan sosial masyarakat ditengah pandemi covid-19 (Sutrisna, 2020). Berdasarkan semua uraian tersebut sangat jelas bahwa pojok baca digital pada masa pandemi seperti ini sangat dibutuhkan pengajaran yang serba online agar dapat diakses mudah dengan mengandalkan smartphone masing-masing individu.

\section{METODE KEGIATAN}

Metode merupakan cara yang digunakan untuk melakukan suatu kegiatan. Metode yang digunakan dalam pengabdian ini yaitu melalui tiga tahap, tahap pra kegiatan, pelaksanaan dan pasca pelaksanaan. Kegiatan pelatihan ini akan dilakukan selama 6 minggu yang dimulai dari tanggal 29 Mei sampai 7 Juli 2020 dan dilaksanakan di desa Gading Kembar, Kecamatan Jabung, Kabupaten Malang. Tahap pertama dalam kegiatan pengabdian ini adalah tahap pra kegiatan. Dengan melakukan diskusi terkait dengan analisis kebutuhan pembelajaran selama pandemic covid-19 di Desa Gading Kembar Bersama dengan perangkat desa dan tenaga pengajar di sekolah yang ada di Desa Gading Kembar. Langkah selanjutnya adalah Menyusun media pembelajaran. Untuk tahap pelaksanaan dilakukan sosialisasi kepada tenaga pengajar beserta murid sekolah, mulai dari TK, SD, SMP dan SMA. Serta tahap terakhir dalam program pengabdian ini adalah melakukan survei terkait dengan hasil sosialisasi yang telah dilakukan.

\section{HASIL DAN PEMBAHASAN}

Proses kegiatan masyarakat diawali dengan melakukan persiapan dengan Menyusun modul yang selanjutnya dibuat pojok baca digital. Dalam tahapan ini disertai pula mendesain cover modul matematika dan mendesain watermark untuk tingkat SD sampai SMA. Modul ini akan disematkan di dalam website yang dimiliki oleh desa. Pengerjaan modul ini dilakukan selama 3 minggu dan pengumpulannya menggunakan format pdf yang diupload melalui website desa Gading Kembar. 

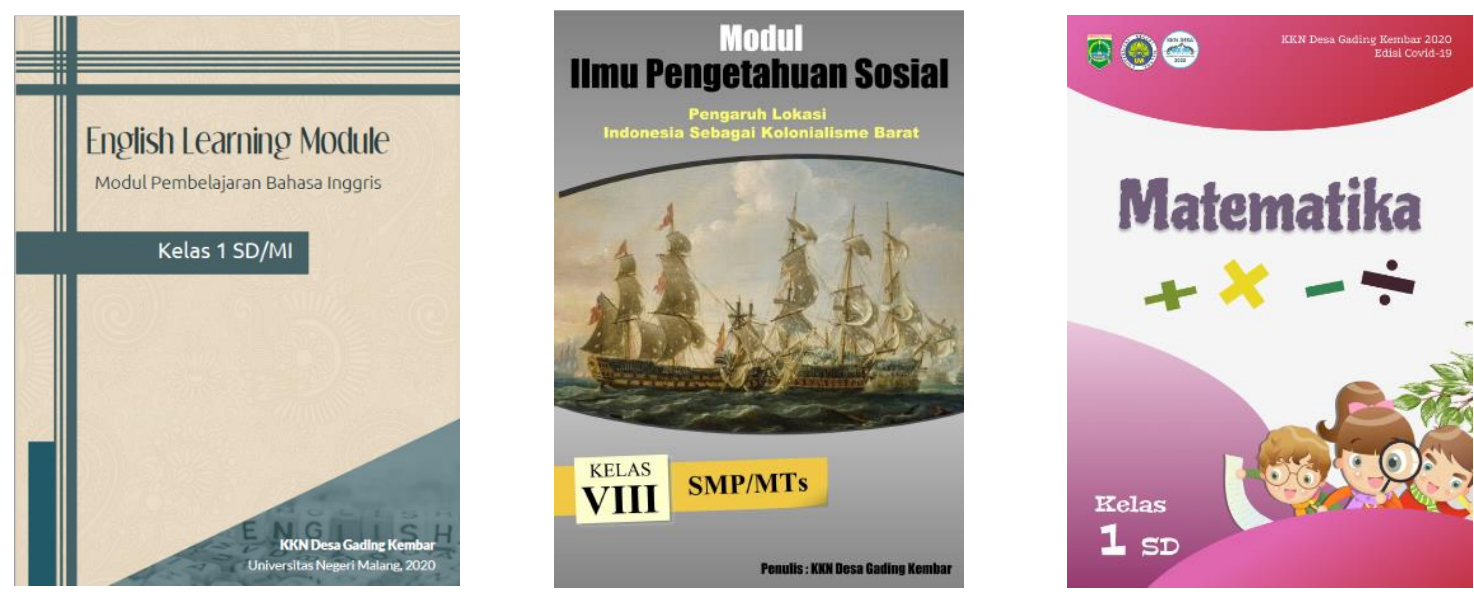

Gambar 1. Cover Modul Matematika SD dan SMP

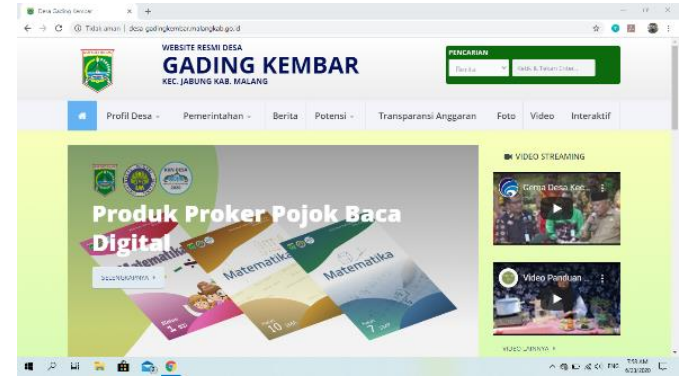

Gambar 2. Tampilan website Desa Gading Kembar

Tahap selanjutnya yaitu pelaksanaan program pengabdian kepada masyarakat. penyuluhan produk program kerja berupa penyuluhan program pojok baca digital. Kegiatan penyuluhan ini dilakukan pada tanggal 30 Juni 2020. Sasaran dari program kerja ini yaitu para guru setingkat PAUD, SD dan SMP yang ada di Desa Gading Kembar, wali murid dari semua tingkat disiplin ilmu, dan beberapa masyarakat seperti ibu PKK desa Gading Kembar. Penyampaian kegiatan ini bertujuan untuk menyampaikan mengenai bagaimana cara akses pojok baca digital, dan konten dari pojok baca digital. Terdapat beberapa hal yang perlu dibenahi pada masyarakat desa Gading Kembar. Salah satunya dalam bidang Pendidikan, yaitu meningkatkan literasi masyarakat dengan membudayakan kebiasaan membaca sejak dini. Penyampaian maksud dari pojok baca digital ini untuk mempermudah masyarakat khususnya beberapa tenaga pendidik dan wali murid yang hadir bisa melakukan pembelajaran secara mandiri kepada murid dan anak mereka di dalam rumah pada masa pandemi Covid-19. Selain itu beberapa modul yang terdapat di dalam pojok baca digital yang ditujukan untuk jenjang TK, SD, SMP, SMA mampu membantu beberapa sekolah yang ada di Desa Gading Kembar sebagai bahan ajar pendamping dalam proses pembelajaran. Selain itu pojok baca digital mampu digunakan beberapa orang tua peserta didik untuk melatih atau mengevaluasi pengetahuan yang di dapat dari pembelajaran yang di sampaikan oleh tenaga pendidikan dengan melakukan pengaksesan pojok baca digital tersebut. 
Ika Zutiasari, Ika Putri Kurniasari, Amirul Fikri, Kholilatul Umiyah, Salsabilla

Nur Rahmawati: Pojok Baca Digital: Media Penunjang Aktivitas Belajar Masa

Pandemi Covid-19
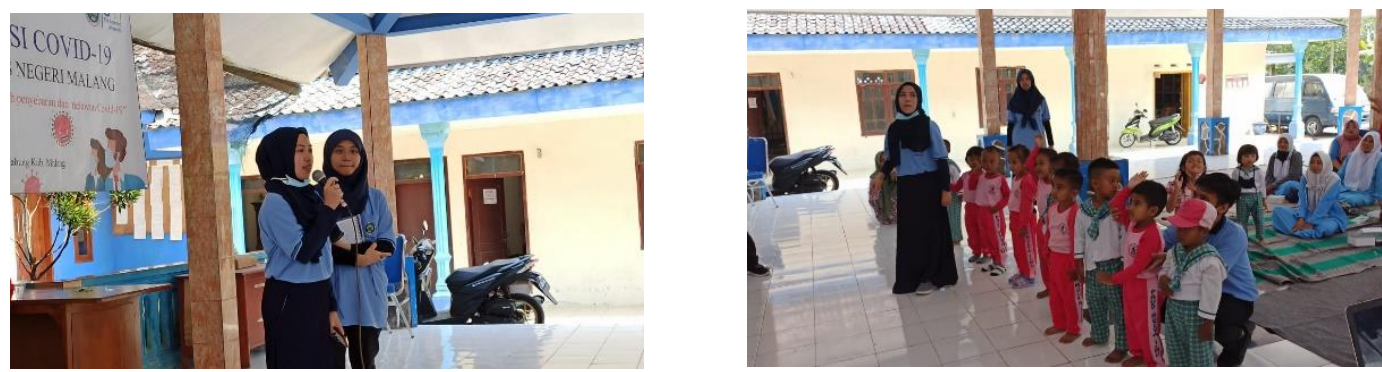

Gambar 3. Penyuluhan Program Pojok Baca Digital

Tahap selanjutnya dalam kegiatan pengabdian ini adalah tahap pasca pelaksanaan. Pada tahap ini penulis memberikan angket evaluasi respon pada masyarakat terhadap modul Pojok Baca Digital. Angket ini diisi oleh 20 peserta pengabdian kepada masyarakat. Hasil angket disajikan pada tabel 1 berikut ini:

Tabel 1. Tabel Evaluasi Respon Masyarakat Setelah Mengikuti Simulasi Akses Pojok Baca Digotal

\begin{tabular}{|c|l|c|c|c|c|}
\hline \multirow{2}{*}{ No } & \multicolumn{1}{|c|}{ Penilaian } & \multicolumn{3}{|c|}{ Persentase Respon Masyarakat } \\
\cline { 2 - 6 } & & $\begin{array}{c}\text { Sangat } \\
\text { Tidak } \\
\text { Setuju } \\
\text { (STS) }\end{array}$ & $\begin{array}{c}\text { Tidak } \\
\text { Setuju } \\
\text { (TS) }\end{array}$ & $\begin{array}{c}\text { Setuju } \\
\text { (S) }\end{array}$ & $\begin{array}{c}\text { Sangat } \\
\text { Setuju (SS) }\end{array}$ \\
\hline 1. & $\begin{array}{l}\text { Bahan ajar modul pada } \\
\text { Pojok Baca Digital yang } \\
\text { disampaikan } \\
\text { mempermudah } \\
\text { pembelajaran }\end{array}$ & $0 \%$ & $0 \%$ & $100 \%$ & $0 \%$ \\
\hline 2. & $\begin{array}{l}\text { Ketertarikan } \\
\text { masyarakat/pelajar } \\
\text { untuk mempelajari } \\
\text { bahan ajar modul Pojok } \\
\text { Baca Digital yang telah } \\
\text { dipaparkan }\end{array}$ & $0 \%$ & $0 \%$ & $90 \%$ & $10 \%$ \\
\hline 3. & $\begin{array}{l}\text { Materi dalam modul } \\
\text { Pojok Baca Digital } \\
\text { sangat jelas dan mudah } \\
\text { dipahami untuk } \\
\text { disampaikan kepada } \\
\text { peserta didik/anak }\end{array}$ & $0 \%$ & $20 \%$ & $65 \%$ & $15 \%$ \\
\hline 4. & $\begin{array}{l}\text { Modul bahan ajar yang } \\
\text { dibuat telah membantu }\end{array}$ & $0 \%$ & $0 \%$ & $100 \%$ & $0 \%$ \\
\hline
\end{tabular}




\begin{tabular}{|c|l|c|c|c|c|}
\hline & $\begin{array}{l}\text { dan mencukupi kriteria } \\
\text { sebagai media } \\
\text { pembelajaran di masa } \\
\text { pandemi Covid-19 }\end{array}$ & & & \\
\hline 5. & $\begin{array}{l}\text { Respon } \\
\text { masyarakat/pelajar } \\
\text { ketika menggunakan } \\
\text { modul Pojok Baca } \\
\text { Digital sebagai } \\
\text { pendamping belajar } \\
\text { mandiri di rumah } \\
\text { dimasa pandemi covid- } \\
19\end{array}$ & $0 \%$ & $0 \%$ & $95 \%$ & $5 \%$ \\
\hline
\end{tabular}

Berdasarkan hasil angket pelaksanaan program pengabdian masyarakat dapat disimpilkan bahwa masyarakat memiliki antusias yang baik dalam mengikuti jalannya simulasi. Terutama wali murid dan tenaga pendidik yang membawa dan menggunakan smartphone, mereka mengikuti mulai dari cara mengakses media pada website milik desa sampai dengan cara mendownload modul. berdasarkan tabel tersebut, diketahui keseluruhan masyarakat menyetujui bahwa bahan ajar dan media Pojok Baca Digital yang disampaikan mempermudah pembelajaran dan telah membantu untuk mencukupi kriteria sebagai media pembelajaran di masa pandemi Covid-19.

\section{KESIMPULAN}

Kegiatan pojok baca digital merupakan salah satu alternatif media yang dapat dimanfaatkan dalam masa pandemic covid-19 oleh masyarakat desa Gading Kembar. Konten yang ada dalam pojok baca digital terdiri atas modul pembelajaran yang ditujukan pada siswa jenjang TK, SD, SMP dan SMA. Selain modul yang memuat beberapa mata pelajaran yang ada pada jenjang tersebut juga terdapat cerpen yang dapat dimanfaatkan bagi siswa pada jenjang PAUD. Berdasarkan hasil penyuluhan terkait program pojok baca digital ini bahwa dari 20 masyarakat yang mengisi angket pelaksanaan program pengabdian kepada masyarakat ini, menunjukkan bahwa masyarakat memiliki antusias yang baik dengan adanya program pojok baca digital ini. Pojok baca digital ini dirasa mampu mempermudah proses pembelajaran bagi siswa pada masa pandemi yang dilakukan secara online.

\section{DAFTAR PUSTAKA}

Asari, A., Kurniawan, T., Ansor, S., Bagus, A., Rahma, N., \& Malang, U. N. (2019). Kompetensi Literasi Digital Bagi Guru Dan Pelajar di Lingkungan Sekolah Kabupaten Malang. 3, 98-104.

Fadli, R. I., Nugraha, A. S., Raharjo, R. P., Sulton, A., \& Sari, R. H. (2020). Model Pembelajaran Inovatif Guru Sma Abdul Hadi. 01(01), 1-12. 
Ika Zutiasari, Ika Putri Kurniasari, Amirul Fikri, Kholilatul Umiyah, Salsabilla Nur Rahmawati: Pojok Baca Digital: Media Penunjang Aktivitas Belajar Masa Pandemi Covid-19

Ghofur, A., Rachma, A., Lamongan, S. P., Sunan, J., \& Kabupaten, K. (2019). Pemanfaatan Media Digital Terhadap Indeks Minat Baca Masyarakat Kabupaten Lamongan. 4(2), 85-92.

Habiburrahman, \& Fatmawati, R. (2020). Peningkatan Minat Baca dan Literasi Digital Melalui Pojok Baca Interaktif Ramah Anak. Abdi Humaniora, 1(2), 57-64.

Herlina, V., \& Yarmi, G. (2019). Pengembangan Buku Cerita Anak Digital Berbasis Literasi Digital pada Siswa Kelas V Sekolah Dasar. Dinamika Sekolah Dasar, 1-13.

Malang, U. N. (n.d.). Petunjuk KKN Edisi COVID-19.

Sutrisna, I. P. G. (2020). Gerakan Literasi Digital Pada Masa Pandemi Covid-19. Stilistika: Jurnal Pendidikan Bahasa Dan Seni, 8, 268-283.

Yusa, M., Hadinegoro, A., \& Fatkhurohman, A. (2018). Implementasi Teknologi Tepat Guna Kepada Masyarakat. Seminar Hasil Pengabdian Masyarakat, ISSN 2615-(April), 4954. 